Gut, 1980, 21, 985-989

\title{
Demonstration of IgA and secretory component in human hepatocytes
}

\author{
SU-MING HSU* AND PEI-LING HSU \\ From the Department of Pathology, Rhode Island Hospital, and Division of Biology and Medicine, \\ Brown University, Providence, Rhode Island, USA
}

SUMMARY By the immunoperoxidase technique, immunoglobulin A (IgA) was demonstrated in $50 \%$ of human hepatocytes. The positively stained cells showed a tendency towards periportal clustering. Very few plasma cells were identified in the liver. The intrahepatocyte IgA is most probably derived from serum and on its way to the bile ducts. Secretory component (SC) had the same distribution as that of IgA.The presence of SC in the hepatocytes reflects either the synthesis of SC or the transport of pre-assembled SC-IgA by liver cells. The significance of transfer of IgA from serum into bile is as yet unknown. However, the transhepatic passage of IgA may represent a reinforcement of local intestinal immunity, as part of the gut-originated IgA antibodies, which fail to go through the intestinal mucosa, may still gain access to the lumen of the gut.

The predominant immunoglobulin (Ig) in the bile of several species, including human, is immunoglobulin A (IgA) of the secretory type ${ }^{1-5}$ Several recent studies have suggested that the biliary $\operatorname{IgA}$ is derived from the serum. ${ }^{6} 7$

The circulating Igs, before going into the bile, must cross two successive cell layers: (1) the endothelial cells between the blood and the intestinal fluid, and (2) the cells between the fluid and the lumen of the bile ducts, which consist of either hepatocytes or biliary epithelium, depending on whether protein transfer takes place within the liver lobules or in the portal spaces.

The present work was therefore undertaken to verify the role of liver cells or biliary epithelium in the transport of IgA. Using the highly sensitive immunoperoxidase technique, IgA was demonstrated mainly in the liver cells.

\section{Methods}

\section{TISSUES}

A total of 10 liver specimens were selected for immunoperoxidase studies. Seven specimens were obtained from necropsy cases within two hours of post mortem examination, and another three were

*Address for reprint requests: Su-Ming Hsu, MD, Department of Pathology, Rhode Island Hospital, Providence, Rhode Island, USA 02902

Received for publication 22 July 1980. obtained as paraffin blocks of wedge biopsies which were done for staging of Hodgkin's disease. None of these cases had a history of liver disease, abnormal liver function test, or alcoholism. The specimens were immediately fixed in $10 \%$ buffered formalin for four hours at room temperature and then dehydrated and embedded in paraffin wax as in routine processing.

All the selected specimens were interpreted as normal by histological examination.

\section{IMMUNOPEROXIDASE STAINING}

The present studies were carried out using the unlabelled antibody method described previously. ${ }^{89}$ Rabbit antisera (IgG fraction) to human IgG, IgM, IgA (specific for heavy chains) or secretory component (Dakopatts, Accurate, NY) were used as the primary antisera.

Serial sections were cut $(5 \mu \mathrm{m})$ from paraffin blocks. The sections were deparaffinised in xylene and processed to alcohol. Trypsinisation was performed to enhance the staining intensity. ${ }^{10}$ Endogenous peroxidase activity was blocked in methanolic $\mathrm{H}_{2} \mathrm{O}_{2}$ for 30 minutes. To reduce the nonspecific background staining, the sections were pretreated with normal, non-immune, swine serum $(1: 10)$ for 10 minutes before the application of the primary antiserum $(1: 400)$. Swine anti-rabbit IgG serum (1:50) (Dakopatts) was then applied, which was followed by rabbit anti-peroxidase-peroxidase complex (1:200) (Dakopatts).

Each stage lasted 30 minutes and was followed by 
washing with three changes of tris-buffered saline, pH 7.6 for 30 minutes. The diaminobenzidine (DAB) (Sigma) reaction was used to localise the site of peroxidase. After development in DAB solution, the sections were rinsed in distilled water, osmicated,11 and counterstained with methylgreen $(1 \%$ in methanol).

\section{SPECIFICITY OF ANTISERA AND CONTROLS}

The specificity of antiserum was confirmed by two criteria: (1) no cross-reactivity was found among different antiserum preparations by double immunodiffusion in agar gel; (2) after absorption of each antiserum with the corresponding antigen on Sepharose 4B beads (prepared as described by Streefkerk et al. ${ }^{12}$ ), the staining activity of the antiserum was completely abolished. No diminution or blocking of staining was noted when the antiserum was absorbed with heterologous antigens.

Additional controls for the staining procedure were also carried out as described by DeLellis et al. ${ }^{13}$ To test for the non-specific binding of antiserum, tris buffered saline or non-immune serum were used as substitutes for each step and the results were consistently negative.

\section{Results}

\section{HEPATOCYTES}

In all sections studied, the hepatocytes reacted positively with anti-IgA antibody, but the intensity of staining varied considerably from cell to cell. Positively stained cells occurred in groups or as isolated units with sorne tendency towards periportal clustering (Fig. 1). It was estimated that about $50 \%$ of the liver cells showed an appreciably positive reaction for IgA. The same was true for the secretory component (SC), although the staining intensity was much lower (Fig. 2A, B).

Positive staining with less intensity for IgG and IgM was also observed in about $20 \%$ and $10 \%$ of the hepatocytes respectively, which were scattered singly or in groups (Table).

Because of the difficulty of identifying the luminal borders of the bile canaliculi under light microscopy,

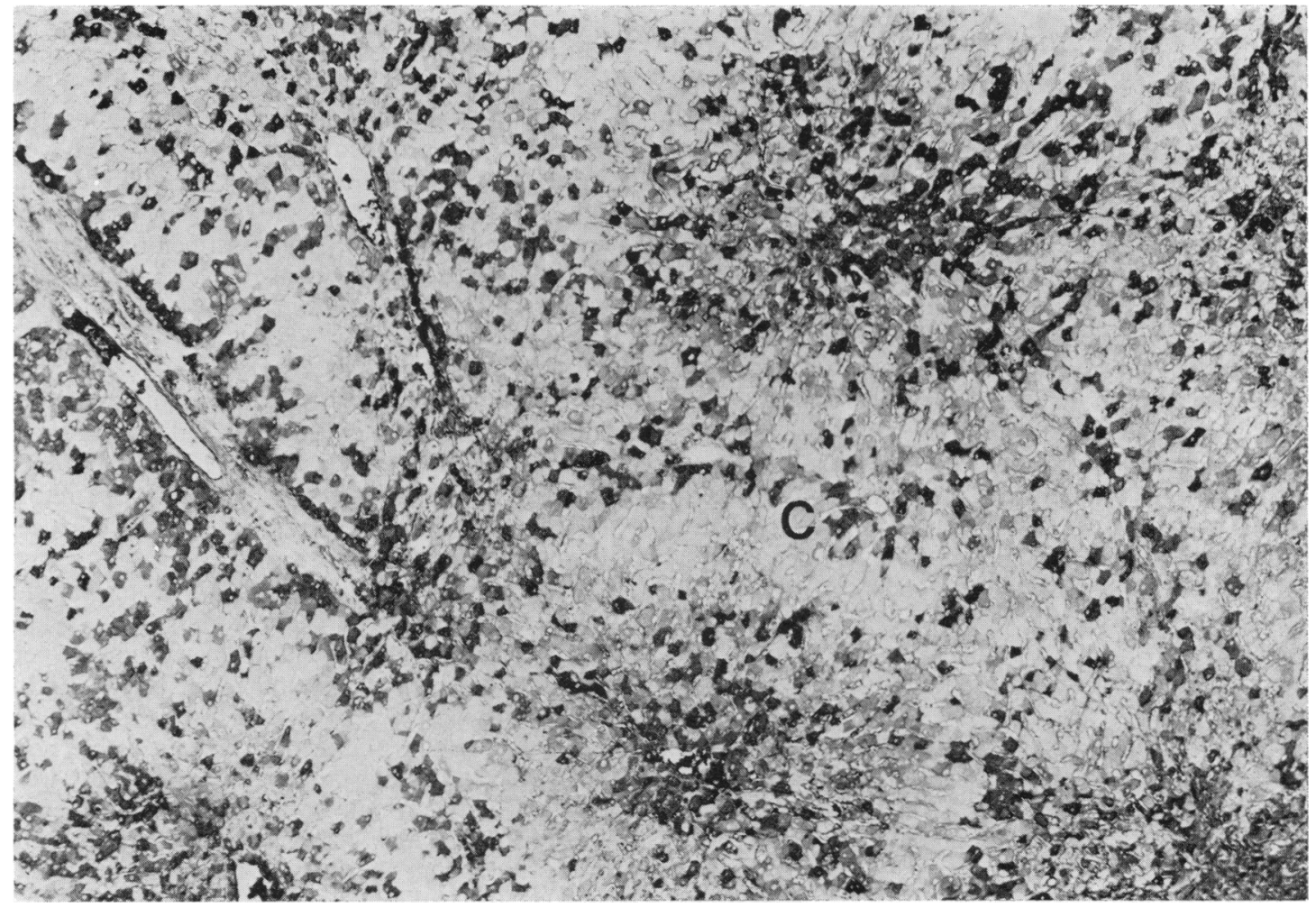

Fig. 1 Hepatic tissue stained for IgA. Note the anatomical distribution with a tendency towards periportal clustering of the IgA-positive hepatocytes. There are only a few positive stained cells scattered singly in the region of central lobule $(C) . \times 25$. 

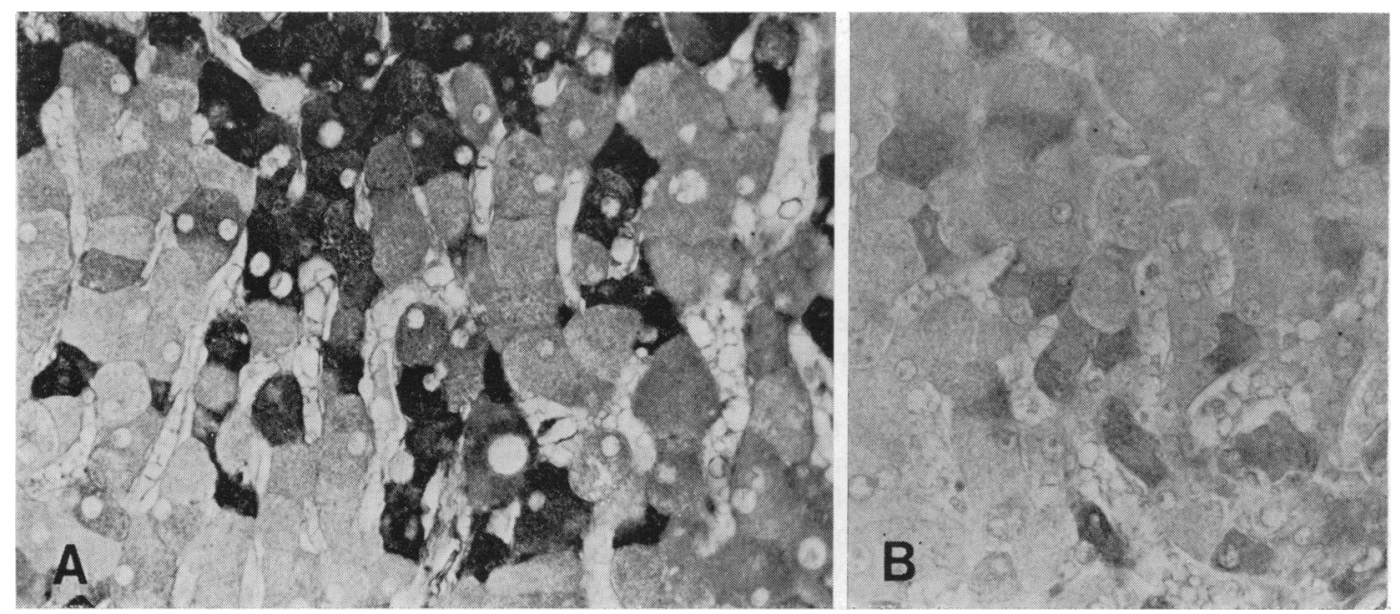

Fig. 2 A. High magnification of IgA-positive hepatocytes shown in Fig. $1, \times 600$. B. Secretory component positive hepatocytes. $\times 600$. (Note: This photomicrograph has been overdeveloped to enhance morphological detail, the staining intensity of $S C$, therefore, was weaker than that for $\operatorname{Ig} A$ ).

Table Immunoenzymatic localisation of immunoglobulins and secretory component in livers

\begin{tabular}{lll}
\hline $\begin{array}{l}\% \text { of cells stained with } \\
\text { staining intensity }\end{array}$ & Hepatocytes & $\begin{array}{l}\text { Epithelial cells of } \\
\text { intrahepatic bile duct }\end{array}$ \\
\hline SC and IgA & $50 \%(+++) *$ for IgA & $10 \%(+$ or ++$)$ \\
IgG & $20 \%(+)$ for SC & None \\
IgM & $10 \%(+$ or \pm$)$ & None \\
\hline
\end{tabular}

*Staining intensity was assigned semiquantitatively, as +++ , strong positive (brown-black); ++ , positive (brown); + , weak positive (light brown); \pm , equivocal; -, negative.
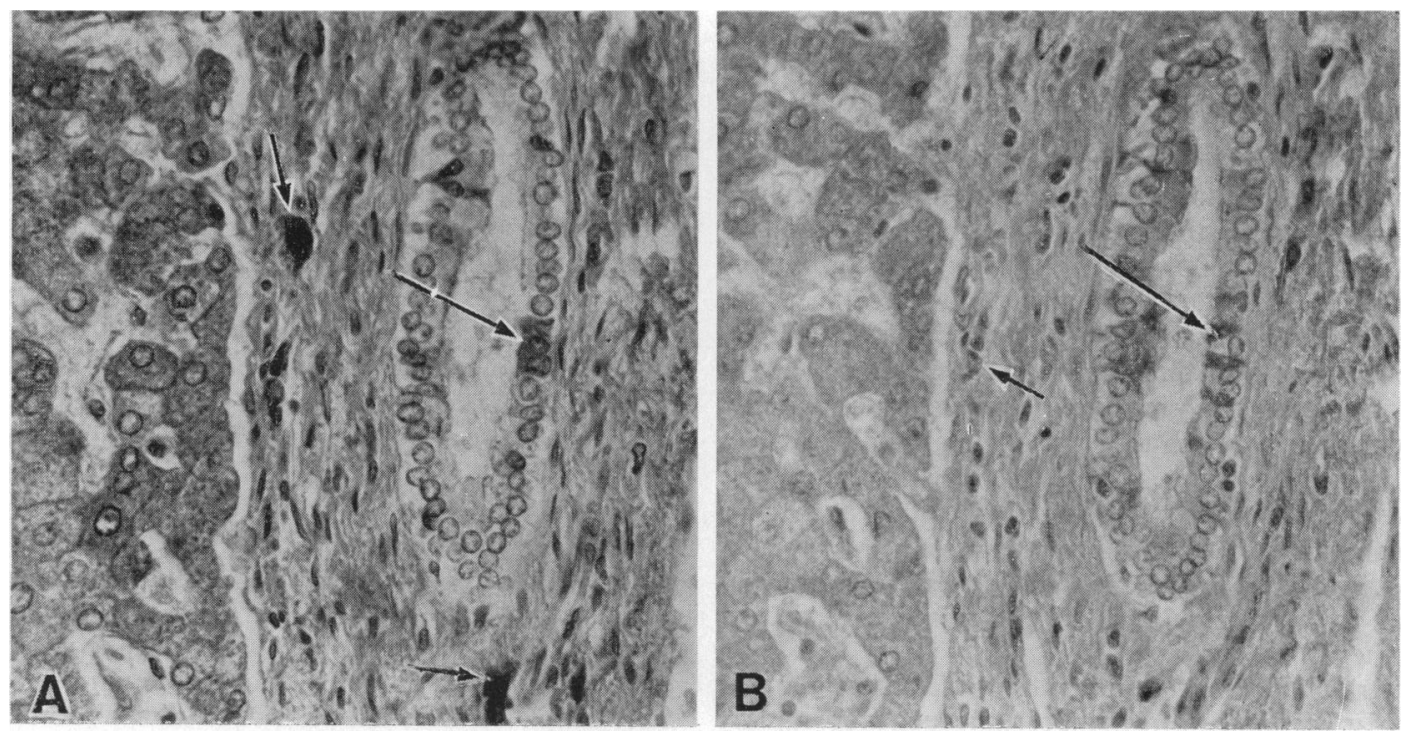

Fig. 3 A. Intrahepatic bile duct. The plasma cells (short arrows) and scattered epithelial cells (long arrow) are positive for IgA. $\times 600$ B. Stained for secretory component. Few biliary epithelial cells are definitely stained (long arrow). Note the non-stained plasma cells (short arrow). $\times 600$. 
the presence or absence of Igs in the bile canaliculi could not be ascertained.

\section{BILIARY EPITHELIUM}

Both IgA and SC could be demonstrated in the epithelium of intrahepatic bile ducts (Fig. 3A, B). However, the percentage of positively stained epithelial cells varied from one duct to another, being less than $10 \%$. In the cells stained, the staining was generally more prominent in the supranuclear cytoplasm.

Very few plasma cells were identified in the adjacent interstitium. It was noted that such plasma cells contained IgA but not SC. In most of the bile ducts examined, the presence of IgA in the biliary epithelium appeared to be associated with the presence of local plasma cells. Yet, as the number of plasma cells was very low, the precise origin of intraepithelial IgA remained unclear.

The staining for IgG and IgM was not identifiable in the epithelium of the intrahepatic bile ducts.

\section{Discussion}

Using the immunoperoxidase technique, IgA, IgG, and IgM were demonstrated in a large population of human hepatocytes, although the staining intensity varied considerably from cell to cell. As the staining reagents used were considered to be specific by several criteria, it seemed unlikely that the observed staining results were due to the non-specific binding of the antisera preparation. Particularly noteworthy was the high percentage of liver cells that were stained with IgA, and the presence of SC in the liver cells.

For many years, it has been known that liver cells are capable of transferring serum proteins, such as albumin, orosomucoid, transferrin, immunoglobulins, and hormones into the bile. ${ }^{12}$ In most cases, the passage of serum proteins into the bile is influenced by their molecular sizes and is directly proportional to their serum concentrations. ${ }^{12}$ It is also noted that glycoproteins, in general, are cleared by passing through the liver. ${ }^{14}$ Thus, as all Ig molecules are glycoprotein in nature, it is likely that the liver mediates their transfer in a manner analogous to the transfer of non-Ig molecules. In this respect, biliary $\operatorname{IgA}$ is unique in that its relative concentration to other proteins in the bile greatly exceeds that in the serum. ${ }^{13-5}$.

Orlans et al. ${ }^{6}$ has shown that injected oligomeric ${ }^{125} \mathrm{I}$-IgA disappears from the serum much more rapidly than $\operatorname{IgG}_{2}$. This rapid disappearance of injected IgA is not seen in rats with ligated bile ducts. Also, in rats with cannulated bile ducts, the labelled IgA appears rapidly in the bile with about $25 \%$ of the injected radioactivity being recovered in three hours. ${ }^{6}$ Lemaitre-Coelho et al. $^{5}$ reported that the ligation of the bile ducts in rats induced a rapid and progressive rise of the secretory $\operatorname{IgA}$ in the serum. The rise was reversible if the bile duct was reopened. These studies support the theory that IgA molecules are selectively transported from serum into the bile.

In theory, the passage of IgA from serum into bile can occur either through the hepatocytes or via the bile duct epithelium. Recently, using autoradiography and electromicroscopy, Birbeck et al. ${ }^{7}$ showed that, shortly after the injection of ${ }^{125}$ Ipolymeric IgA into rats, the IgA molecules became bound to the plasma membrane of hepatocytes, and, after 30 minutes, much of it was transported across the cytoplasm and became localised around the bile canaliculi. This result leads to the conclusion that rat hepatocytes do provide a route for the passage of IgA. Our studies demonstrating the presence of IgA in human hepatocytes is consistent with the above mechanism. Although our immunoperoxidase study did demonstrate the presence of IgA and SC in some biliary epithelial cells, the majority of the epithelial cells remained unstained by anti-IgA and anti-SC antisera. Moreover, the presence of IgA in the biliary epithelium tends to be associated with the presence of local plasma cells which occur rather infrequently. At the present time, we are unable to determine whether the intrabiliary epithelial IgA is derived from the serum or is synthesised by local plasma cells, or both.

Since the beginning of this study, there has been one report which contradicts our data. Using peroxidase labelled antibody and electromicroscopy, Smith et al. ${ }^{15}$ conducted a study from one liver specimen and concluded that IgA was not present in human hepatocytes and that serum IgA appeared to be transported by the biliary epithelium rather than the hepatocytes. The discrepancy between their result and the present study may be due to the differences in the amplification of the antigenantibody reaction, the method of detection, and the areas of liver examined.

The mechanism of passage of IgA through human hepatocytes is not completely understood. In the rat, it was found that monomeric IgA and secretory IgA (SC-IgA) were transported poorly when compared with polymeric IgA without SC..$^{14}$ Moreover, the majority of $\operatorname{IgA}$ in the bile is of secretory type; ${ }^{1415}$ it appears that the trans-hepatocyte transport of $\operatorname{IgA}$ requires prior combination with SC. ${ }^{14}$ Similar studies have not been done in humans. However, in this study, the presence of SC in human hepatocytes is consistent with the idea that SC might act as the liver cell receptor for polymeric 
IgA and mediate its transfer into the bile spaces. ${ }^{16} 17$ Alternatively, some of the SC detected in the liver cells may also come from preassembled $\operatorname{IgA}$ (or IgM).

The transfer of small amounts of IgG and IgM through hepatocytes is likely to occur through a mechanism common to all macro-molecules. ${ }^{12}$ The higher number and greater intensity of IgG positive hepatocytes compared with IgM-positive hepatocytes probably reflects the higher serum concentration and lower molecular weight of IgG. However, as IgM also has the ability to bind SC, it may also be transported through an SC-mediated mechanism. ${ }^{17}$ In any event, the ability of liver cells to transfer all classes of Igs indicates that liver cells may play an important role in regulating serum Ig concentrations. Failure to excrete Igs into bile may contribute, in part, to the hypergammaglobulinaemia and raised serum IgA and SC observed in many patients with micronodular cirrhosis or extrahepatic biliary obstruction. ${ }^{18}$

\section{References}

'Dive CH, Nadalini RA, Vaerman JP, Heremans JF. Origin and nature of the proteins of bile, II. Europ $J$ Clin Invest 1974 ; 4 : 241-46.

${ }^{2}$ Dive CH, Heremans JF. Nature and origin of the proteins of bile, I. Europ J Clin Invest 1974; 4: 235-39.

${ }^{3}$ Tomasi TB, Jr. The immune system of secretions. Englewood Cliffs, NJ : Prentice-Hall, 1976.

"Leslie GA, Stankus RP, Martin LN. Secretory immunological system of fowl. $V$ Int Arch Allergy Appl Immunol 1976; 51 : 175-85.

${ }^{5}$ Coelho-Lemaitre I, Jackson GDF, Vaerman VP. High levels of secretory $\operatorname{IgA}$ and free secretory component in the serum of rats with bile duct obstruction. $J$ Exp Med 1978; 147: 934-39.
${ }^{6}$ Orlans E, Peppard J, Reynolds J, Hall J. Rapid active transport of immunoglobulin $\mathrm{A}$ from blood to bile. J Exp Med 1978; 147: 588-92.

${ }^{7}$ Birbeck MSC, Cartwright P, Hall JG, et al. The transport by hepatocytes of immunoglobulin $\mathbf{A}$ from blood to bile visualised by autoradiography and electron microscopy. Immunology 1979; 37: 477-84.

${ }^{8}$ Sternberger LA. Immunocytochemistry. Englewood Cliffs, NJ: Prentice-Hall, 1976.

${ }^{9}$ Hsu SM, Ree HJ. Self-sandwich method: an improved immunoperoxidase technique for the detection of small amounts of antigens. Am J Clin Pathol 1980. (In press.)

${ }^{10}$ Curran RC, Gregory J. Demonstration of immunoglobulin in cryostat and paraffin sections of human tonsil by immunofluorescence and immunoperoxidase techniques. J Clin Pathol 1978; 31 : 974-83.

${ }^{11 B u s a c h i}$ CA, Ray MB, Desmet VJ: An immunoperoxidase technique for demonstrating membrane localized HBsAg in paraffin sections of liver biopsies. $J$ Immunol Meth 1978; 19: 95-9.

${ }^{12}$ Streefkerk JG, van der Ploeg M, Kors N: Some aspects of immunoperoxidase reactions in the agarose bead model system Ann NY Acad Sci 1975; 254: 212-22.

${ }^{13}$ DeLellis RA, Sternberger LA, Mann RB, et al. Immunoperoxidase technics in diagnostic pathology. Am J Clin Pathol 1978; 71 : 235-39.

${ }^{14}$ Fisher NM, Nagy B, Bazin H, Underdown BJ: Biliary transport of IgA: Role of secretory component. Proc Natl Acad Sci 1979; 76: 2008-12.

${ }^{15}$ Smith PD, Nagura H, Brown WR: IgA in human bile and liver. Gastroenterology (Abstract) 1979; 76: 1251.

${ }^{16}$ Socken DJ, Jeejeebhoy KN, Bazin H, Underdown BJ: Identification of secretory component as an IgA receptor on rat hepatocytes. J Exp Med 1979; 150: 1538-43.

${ }^{17}$ Orlans E, Peppard J, Fry JF, et al. Secretory component as the receptor for polymeric IgA on rat hepatocytes. J Exp Med 1979; 150: 1577-82.

${ }^{18}$ Thompson RA, Carter R, Strokes RP, et al. Serum immunoglobulins, complement levels and autoantibodies in liver disease. Clin Exp Immunol 1973; 14: $335-46$. 